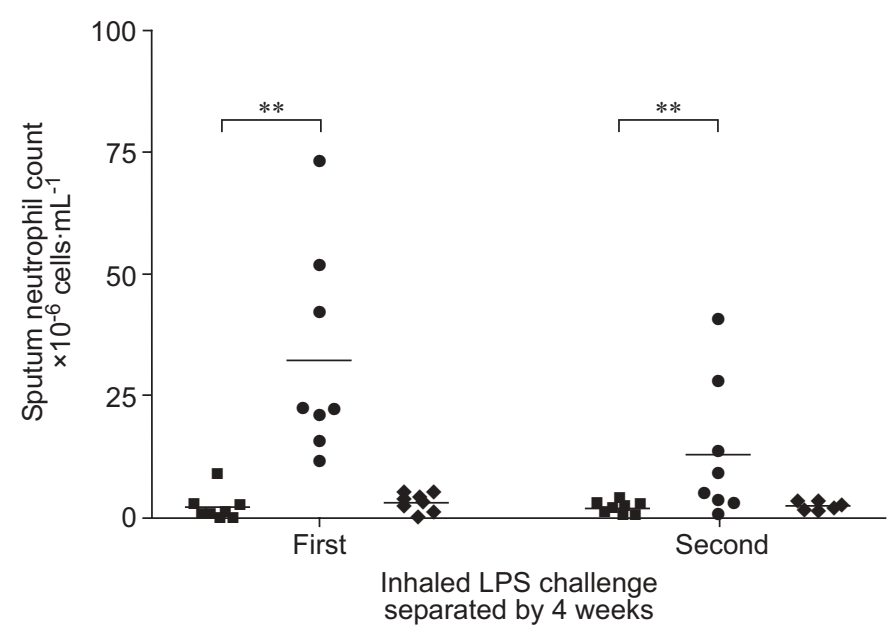

FIGURE 1. Comparison of sputum neutrophilia post-inhaled lipopolysaccharide (LPS; 6 th $h$ ) between two inhaled LPS challenges separated by 4 weeks. baseline; $\bullet: 6 \mathrm{~h}$ post-inhaled LPD; $\bullet 1$ week post-inhaled LPS. **: denotes $p=0.01$ between the mean differences.

LPS on two occasions separated by $\geqslant 3$ weeks. However, none of these studies had observed tolerance towards subsequent LPS challenge(s) in their healthy human subjects at doses of LPS described that were higher than ours. It is possible that tolerance in healthy nonatopic human subjects only occurs in exposure to lower doses of inhaled endoxin. In fact, existing literature indicates that exposure of 30-40 $\mu \mathrm{g}$ inhaled LPS is probably the clinical threshold to induce symptoms and lung function changes for healthy subjects [4].

More research is required to validate our preliminary observation.

\section{L.C. Loh}

Dept of Medicine, Clinical School, International Medical University, Jalan Rasah, Malaysia.

\section{REFERENCES}

1 Bals R. Lipopolysaccharide and the lung: a story of love and hate. Eur Respir J 2005; 25: 776-777.

2 Wallin A, Pourazar J, Sandstrom T. LPS-induced bronchoalveolar neutrophilia; effects of salmeterol treatment. Respir Med 2004; 98: 1087-1092.
3 Michel O, Nagy AM, Schroeven M, et al. Dose-response relationship to inhaled endotoxin in normal subjects. Am J Respir Crit Care Med 1997; 156: 1157-1164.

4 Thorn J. The inflammatory response in humans after inhalation of bacterial endotoxin: a review. Inflamm Res 2001; 50: 254-261.

DOI: 10.1183/09031936.05.00058405

From the author:

The study that L.C. Loh describes in his letter above adds another interesting aspect that is critical for the response to inhaled endotoxin.

Lipopolysaccharide tolerance is a well-known feature of several host defence cells, although the mechanisms involved are not entirely clear [1]. Tolerance has also been shown to be associated with various cellular processes, such as decreased activity of $\mathrm{Gi}$ proteins, protein kinase $C$, mitogen-activated protein kinase, activator protein-1 and nuclear factor- $\mathrm{kB}(\mathrm{NF}-\kappa \mathrm{B})$. Inhibitory molecules such as IRAK-M, suppressor of cytokine-signaling-1 and inhibitor- $\kappa \mathrm{B}$ are found activated. At the nuclear level, the NF- $\kappa$ B subunit p50 homodimer expression and peroxisomeproliferator-activated receptors $-\gamma$ are increased. There is evidence from rodent studies that this phenomenon is also relevant for pulmonary innate immunity [2].

The preliminary results described in this letter support this view and it is likely that this mechanism is of biological relevance, because the lung is constantly exposed to small amounts of lipopolysaccharide. The pulmonary exposure with endotoxin probably has many consequences. At this time it is uncertain where lipopolysaccharide tolerance is functionally located in this scenario.

\section{R. Bals}

Hospital of the University of Marburg, Marburg, Germany.

\section{REFERENCES}

1 Fan H, Cook JA. Molecular mechanisms of endotoxin tolerance. J Endotoxin Res 2004; 10: 71-84.

2 Shimada M, Tsukada $\mathrm{H}$, Ishizuka $\mathrm{O}$, et al. Lipopolysaccharide tolerance in relation to intrabronchial influx of neutrophils in the rat. Lung 2000; 178: 235-248.

DOI: 10.1183/09031936.05.00062205

\title{
Pre-analytical conditions for the assessment of circulating MMP-9 and TIMP-1: consideration of pitfalls
}

\section{To the Editors:}

We read with interest the recent article of HigAshimoto et al. [1], which reported an increased activity of tissue inhibitor of metalloproteinase (TIMP)-1 in patients with chronic obstructive pulmonary disease (COPD) and asthma. In contrast, the molar ratio between matrix metalloproteinase (MMP)-9 and TIMP-1 was significantly lower in COPD patients than in normal subjects. 